\title{
Build up conservation research capacity in China for biodiversity governance
}

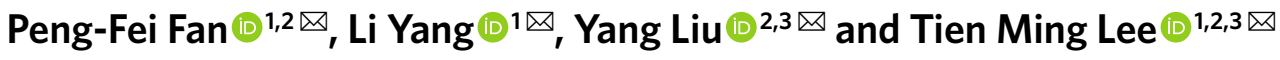

\begin{abstract}
To achieve the grand vision of 'Ecological Civilization' and to build a more sustainable Belt and Road Initiative, China's conservation policies must be underpinned by research. However, recent institutional and vertebrate conservation scientists' publication data suggest that China has a growing conservation research capacity deficit. China lacks a pipeline for the training and development of conservation scientists locally and abroad. The network of active conservation scientists is rapidly shrinking and institutions are exhibiting signs of academic inbreeding. Career advancement policies are perversely incentivized away from practical conservation research, thereby constraining capacity building. Comparative data indicate that China severely lags behind the United States and United Kingdom in research quality and capacity. We outline possible recommendations that include developing a different performance evaluation system, promoting training and international exchanges, encouraging interdisciplinary collaboration, and fostering international collaborative networks for China-based conservation scientists. For global biodiversity governance, China must act to make up for considerable shortfalls in conservation research capacity and research collaborative networks.
\end{abstract}

A s one of the world's 17 megadiverse countries, China supports an exceptionally rich biodiversity including nearly 3,000 vertebrates (excluding fish), of which over $20 \%$ (or 642 species) are found nowhere else in the world ${ }^{1}$. Following decades of rapid economic development, China now faces serious environmental and biodiversity conservation issues ${ }^{2-4}$. Of the known species that were assessed in the Red List of China's vertebrates (excluding fish), over $20 \%$ (637 species) were listed as either vulnerable, endangered or critically endangered ( $26 \%$ of mammals, $11 \%$ of birds, $29 \%$ of reptiles and $43 \%$ of amphibians $)^{5}$.

To balance economic development and environment protection, an ambitious national plan for 'Ecological Civilization' has been proposed. Ecological Civilization states that a good ecological environment is the most beneficial for human well-being and emphasizes that "lucid waters and lush mountains are invaluable assets" 6 . The plan has the goal of achieving human development progress through learning to coexist with nature by promoting sustainability. Globally, China's most ambitious development plan yet, the Belt and Road Initiative (BRI), which aims to promote economic development and inter-regional connectivity of roughly half of the world's population across more than 130 countries, may impact global biodiversity conservation since many of these BRI countries are biodiversity-rich as well $^{7-10}$. To ensure sustainable development, China recently committed to forming the BRI International Green Development Coalition aimed at greening BRI investments ${ }^{11,12}$. Considering recent progress, China could potentially drive long-term green and sustainable development and help many of the participating countries meet their targets for the United Nation's 2030 Agenda for Sustainable Development and therefore shape the global biodiversity conservation outcome over the next few decades ${ }^{12}$.

Ambitious policies require conservation research capacity In order to achieve Ecological Civilization, China has increased investment in natural capital and has contributed substantially to improvements in most ecosystem services ${ }^{13}$. China has also established a more cohesive system for national protected area management by reforming and reorganizing various related agencies, so as to align goals, lessen conflicts, and remove administrative redundancy ${ }^{14,15}$. However, China's environmental investment programmes generally aim to reduce natural disaster risk by restoring forests and grasslands, which lacks a direct link to biodiversity conservation $^{13,16}$. In addition to the direct use benefits provided by ecosystems such as food, fuel and other goods for consumption, species are crucial to the stability and function of ecosystems. Species also provide non-use values consisting of existence, aesthetic, bequest and intrinsic values. As such, we cannot overlook species and biodiversity conservation in the era of Ecological Civilization ${ }^{17}$.

Increasingly, China has been taking on key conservation leadership roles. As a high-profile example, Xinsheng Zhang from China was elected as the president of the International Union for Conservation of Nature (IUCN) in 2016. The city of Kunming in Yunnan Province was to have hosted the Fifteenth Meeting of the Conference of the Parties to the Convention on Biological Diversity (COP15) in 2020, though this has now been postponed due to the COVID-19 pandemic. Nevertheless, China's contribution of species conservation scientists to global conservation mechanisms, such as the IUCN Species Survival Commission (SSC) and the Intergovernmental Science-Policy Platform on Biodiversity and Ecosystem Services (IPBES), remains relatively low. Presently, no Chinese scientists are Chairs, Co-Chairs or Red-List Authority Coordinators of the 53 IUCN SSC vertebrate specialist groups where China is a range state (that is, 21 mammal, 19 bird, and 13 amphibian and reptile groups) and 13 disciplinary groups ${ }^{18}$. As documented, there are only 37 expert contributors from China for the IPBES assessments (for comparison, the United Kingdom has 54) ${ }^{19}$. This is concerning because the dearth of experts in key positions may signal shortfalls in conservation training and research capacity.

'School of Life Sciences, Sun Yat-sen University, Guangzhou, China. ${ }^{2}$ School of Ecology, Sun Yat-sen University, Shenzhen, China. ${ }^{3}$ State Key Laboratory of Biological Control, Sun Yat-sen University, Guangzhou, China.凶e-mail: fanpf@mail.sysu.edu.cn; yangli53@mail.sysu.edu.cn; liuy353@mail.sysu.edu.cn; tienminglee@gmail.com 


\section{Vertebrate conservation as a case study}

Across all species groups, vertebrates have received the most attention in both research and conservation. In 2016, the Chinese Academy of Sciences and Ministry of Ecology and Environment of the People's Republic of China released a Red List of China's Vertebrates more than a decade after the first China Species Red List was published ${ }^{5}$. Although some iconic species, such as the giant panda (Ailuropoda melanoleuca) which has received massive conservation and research efforts resulting in a population increase of nearly $17 \%$ from 2004 to $2015^{20}$, many others have become extinct or extirpated in China ${ }^{5}$. For instance, the northern white-cheeked gibbon (Nomascus leucogenys) received far less research emphasis and became extirpated recently in China ${ }^{21}$. Regional conservation research involving China-based scientists appeared to benefit and improve the conservation status of threatened vertebrate species, pointing to the importance of research capacity, particularly when it comes to providing crucial knowledge of species biology, ecology, behaviour, and population threats ${ }^{22}$. However, this is only a vital first step in filling the research-action gap, which could be a substantial barrier to conservation success ${ }^{23}$. We believe that the conservation status and trends of vertebrate taxa only represent the tip of the iceberg of biodiversity conservation in China. Using the research status of vertebrates as a best-case scenario case study, we highlight numerous issues and trends that will likely hinder and compromise China's progress for biodiversity conservation.

\section{Estimating research capacity in vertebrate conservation}

In China, conservation biology is not regarded as a key discipline, and it is challenging to identify conservation biologists since the field of conservation is multi-disciplinary and inter-disciplinary. To illuminate the shortfall in conservation capacity, we searched for scientists whose research direction related to mammal (including marine), bird, reptile and amphibian conservation (we thereafter refer to them as vertebrate conservation scientists). We excluded those studying fish because most are involved in aquaculture and do not contribute directly to biodiversity conservation. We screened their stated research direction and recent publications as revealed on their online research profiles (for example, institute homepages) from 137 'Double First-Class Disciplines' universities and 8 institutes of the Chinese Academy of Sciences (CAS). These institutions are arguably the best research institutions in China, and play a vital role in scientific research and training of $\mathrm{PhD}$ students. Other small or local universities may have majors related to vertebrate conservation, but because they have no or only small $\mathrm{PhD}$ programmes, they will likely have a negligible contribution to building up research capacity in the near future. These vertebrate conservation scientists were trained in either ecology, behaviour, zoology, genetics, biogeography, conservation planning, ecosystem services evaluation, or environmental science. We then searched for publications in five recent years (from 2014 through 2018) for each conservation scientist.

We assessed conservation-related publications of every vertebrate conservation scientist in the Web of Science Core Collections (WOSCC) in the selected five recent years (2014-2018) (Supplementary Information; Supplementary Tables 1 and 2). We excluded those who have not published any conservation-related paper in the past five years. Specifically, we extracted the title, abstract, keywords, journal information, publication year, and number of citations of every paper, and then filtered the papers using the words "conservation", "Conservation" or "CONSERVATION". If a paper included these terms in the title, abstract or keywords, or the paper was published in a journal that is classified as biodiversity conservation in the WOSCC, we defined it as a conservation-related paper. While this may seem simplistic, because authors may just add 'conservation' to the end of the abstract or keywords without the study having any clear conservation implications, we did not find strong evidence of abuse in our findings. Nevertheless, we acknowledged that we may have misidentified some papers as conservation-related. In addition, while we recognized that creativity and originality of ideas may be more important in many ways than the number of publications and citations, it is beyond the scope of our study to evaluate their impact.

\section{Diminishing conservation research capacity}

We found a total of 205 active vertebrate conservation scientists who published at least one conservation-related paper from 2014 to 2018 from 37 institutions in mainland China (Fig. 1). The two affiliated institutes of CAS, the Institute of Zoology (IOZ) and Kunming Institute of Zoology (KIZ), and Beijing Normal University (BNU) have trained the most vertebrate conservation scientists. Together with the Chengdu Institute of Biology (CIB) of CAS, these four institutions represent the nation's core research and education hubs for vertebrate conservation scientists. However, we found a high level of academic inbreeding (here defined as a scientist taking up employment in the research institution where the $\mathrm{PhD}$ thesis was defended) in three of the four hubs (Fig. 1a), except CIB. This may have a negative impact on research productivity in the long run because academic inbreeding is associated with lower scholarly output and the academically inbred faculty is relatively more focused on its own institution and less open to the rest of the scientific world ${ }^{24}$.

In addition, Chinese institutions have recruited significantly fewer vertebrate conservation scientists since 2008 (Fig. 1b; piecewise linear regression identified two clear break-points in 2002 and 2008, with a decreasing slope of $-1.21(P<0.05)$ between 2008 and 2018). One possible reason for the overall decline of this group of scientists is related to the perverse incentivizing scheme tied to individual and institutional performance evaluation primarily based on the journal impact factors ${ }^{25}$. Since 2004, the four-tier impact-factor-based journal ranking system proposed by CAS (www.fenqubiao.com) has been widely adopted by nearly all Chinese universities and research institutions to recruit and reward early-career scientists to publish in high impact factor journals. Because the impact factors of conservation journals (for example, Conservation Letters, Conservation Biology, Biological Conservation, Journal of Animal Ecology, Journal of Applied Ecology, Diversity and Distributions, Animal Conservation and $\operatorname{Oryx}$ ) are lower compared to many journals in cell biology and molecular biology, conservation scientists are in a disadvantaged position when competing for limited resources with fellow departmental colleagues specializing in other life-sciences fields. In order to publish papers in high impact factor journals, some scientists have shifted their research away from time-consuming field-based ecology and conservation research to areas such as genome biology and cell biology ${ }^{26}$.

In 2008, the Chinese government introduced a plan to rapidly build up scientific research capacity in China by attracting qualified early-career overseas scholars ${ }^{27}$. By the end of 2018, nearly 4,000 young scientists from overseas had returned to China to work full-time but only three of them (including two foreigners) are vertebrate conservation scientists, creating negligible impact for the local conservation scientific community. Even worse is that career advancement and graduate student training in China is overly dependent on the impact factors of the journals where the work is being published. This probably reduced the number of PhD students and stymied the growth and development of the field of vertebrate conservation science. While other related scientific disciplines are improving globally (that is, Earth and environmental sciences in Nature Index), vertebrate conservation scientists in China are ageing prematurely and even in decline (Fig. 1b).

\section{Comparing research capacity in the UK and US}

To evaluate the disparity in conservation research capacity between China and other leading countries, we used the same method to 

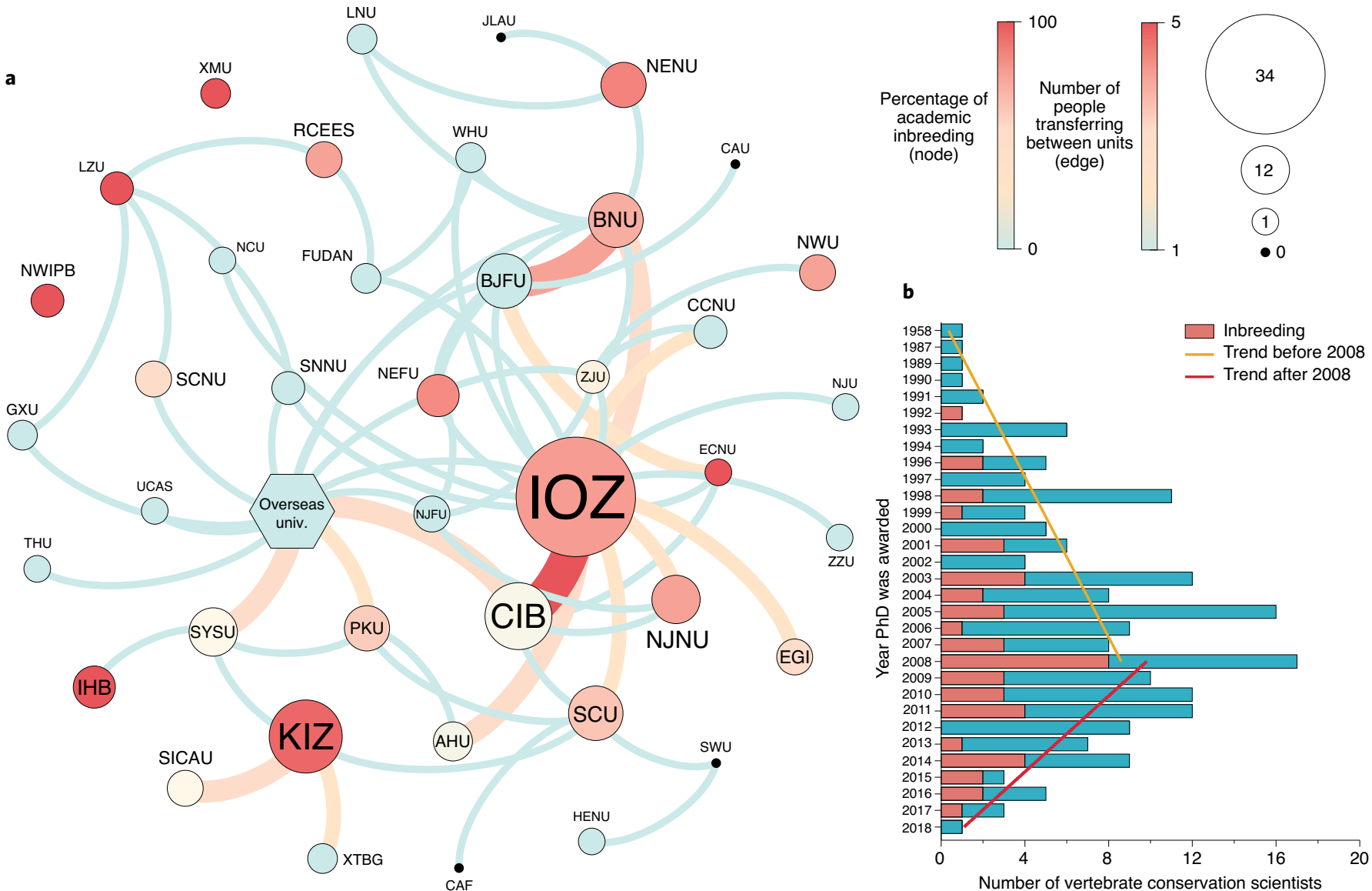

Fig. 1 Active vertebrate conservation scientists in Chinese leading universities and research institutes. a,b, Distribution (a) and population pyramid (b) of 205 active vertebrate conservation scientists. Each node (circle) represents an institution. The size of the circle represents the number of vertebrate conservation scientists in the institution. The colour of each circle represents the percentage of academic inbreeding. The clockwise direction of the arc indicates people transfer between organizations. The thickness of arc represents the number of transfers. AHU, Anhui University; BJFU, Beijing Forestry University; BNU, Beijing Normal University; CAF, Chinese Academy of Forestry; CAU, China Agricultural University; CCNU, Central China Normal University; CIB, Chengdu Institute of Biology, Chinese Academy of Sciences CAS; ECNU, East China Normal University; EGI, Xinjiang Institute of Ecology and Geography CAS; FUDAN, Fudan University; GXU, Guangxi University; HENU, Henan University; IHB, Institute of Hydrobiology CAS; IOZ, Institute of Zoology CAS; JLAU, Jilin Agricultural University; KIZ, Kunming Institute of Zoology CAS; LNU, Liaoning University; LZU, Lanzhou University; NCU, Nanchang University; NEFU, Northeast Forestry University; NENU, Northeast Normal University; NJFU, Nanjing Forestry University; NJNU, Nanjing Normal University; NJU, Nanjing University; NWIPB, Northwest Plateau Institute of Biology CAS; NWU, Northwest University; Overseas univ., any overseas university; PKU, Peking University; RCEES, Research Center for Eco-Environmental Sciences CAS; SCNU, South China Normal University; SCU, Sichuan University; SICAU, Sichuan Agricultural University; SNNU, Shaanxi Normal University; SWU, Southwest University; SYSU, Sun Yat-sen University; THU, Tsinghua University; UCAS, University of Chinese Academy of Sciences; WHU, Wuhan University; XMU, Xiamen University; XTBG, Xishuangbanna Tropical Botanical Garden CAS; ZJU, Zhejiang University; ZZU, Zhengzhou University.

generate a comparative dataset for the top research institutes in the United Kingdom (UK) and United States (US) (Supplementary Tables 2 and 4, respectively). Because conservation biology was established much earlier in the US and UK than in China, there are far more senior conservation scientists in these two countries. In order to make a fair comparison, we did not compare the total publication and citations for each scientist's entire career. Instead, we compared the number of publications and citations in the past five years. We estimated that there are 474 vertebrate conservation scientists from 54 institutes in the UK and 637 vertebrate conservation scientists from 89 institutes in the US, which are three- and four-times greater than the number of vertebrate conservation scientist per institute in China, respectively (Fig. 2a). Because we are not familiar with all institutions in the US and UK, we might have underestimated the numbers of vertebrate conservation scientists and their publications. However, this will not affect our main conclusions because the missing data will only exacerbate the difference in research conservation capacity with China, for which our data are complete.

On average, $37.1 \%$ (range: $2.3-100 \%, n=205$ ) of the publications of Chinese vertebrate conservation scientists are related to conservation. This number is $38.9 \%$ (range: $1.3-100 \%, n=637$ ) in the US and $44.0 \%$ (range: $1.7-100 \%, n=474$ ) in the UK. Comparing their scientific performance on average, Chinese vertebrate conservation scientists published a mean of $5.2 \pm 5.3$ s.d. conservation-related papers in the past five years (range: 1-45), which is comparable to the performances of the US $(5.4 \pm 5.6$, range: $1-35)$ and UK vertebrate conservation scientists $(6.0 \pm 7.6$, range: $1-58)$ (Fig. $2 b$, Kruskal-Wallis test: $\left.\chi^{2}=0.1, P=0.93\right)$. However, the citations per paper of Chinese scientists $(4.0 \pm 5.6)$ are less than half of those for US $(9.6 \pm 14.9)$ and UK $(9.6 \pm 19.7)$ scientists (Fig. 2c, KruskalWallis test: $\left.\chi^{2}=61.1, P<0.01\right)$.

To assess if this is a problem facing conservation and not a wider issue with Chinese science which would require a different 
a

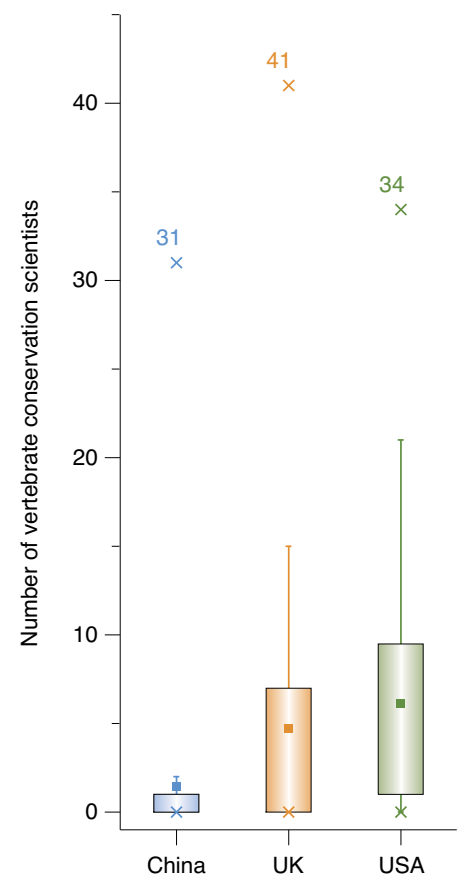

b

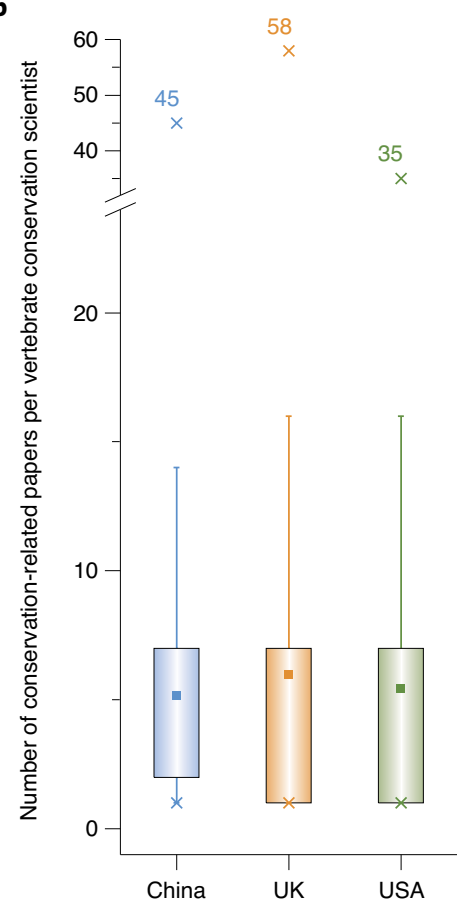

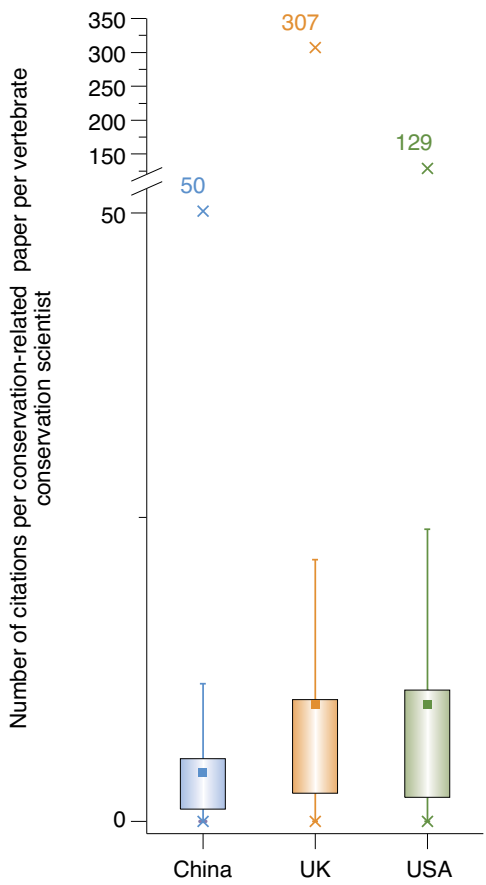

Fig. 2 | How China compares with the UK and US in conservation science research capacity. a-c, Number of vertebrate conservation scientists per institution (a), their performance (b; number of conservation-related papers published in five recent years) and mean number of citations per conservation-related paper for each vertebrate conservation scientist (c) in China ( $n=145$ institutions), the United Kingdom ( $n=101)$ and United States $(n=104)$. Box plots show means (squares) and each box is bounded by the 25 th and 75 th percentiles (interquartile range). The whiskers extend to the 5 th and 95th percentiles, with the maximum value shown above each plot. Outliers are indicated by crosses.

mechanism to tackle it, we examined a different relevant dataset. We checked the distribution of the 2019 Essential Science Indicators (ESI) highly cited researchers across key scientific disciplines among the countries ${ }^{28}$. The ESI highly cited researchers are the world's most influential researchers of the past decade. To qualify, they must have published multiple highly cited papers that are ranked in the top $1 \%$ by citations for field and year in the WOSCC. We found that there was a total of 636 highly cited researchers from mainland China in 2019 , ranking only after the US $(2,848)$, while the UK has 549 . Of those in the non-life sciences fields, 72 are working in chemistry (79 in the US and 7 in the UK), 63 in engineering (23 and 5), 65 in materials sciences (75 and 7), and 43 in computer sciences (15 and 9). It is clear that China appears to be influential and competitive with the US and UK in these disciplines.

However, this is not the case in the life-sciences disciplines, in which vertebrate conservation scientists are mostly trained. There are 10 or fewer researchers in each of the fields of biology and biochemistry (105 in the US and 27 in the UK), neurobiology and behaviour (116 and 31), immunology (80 and 6), microbiology (85 and 4), plant and animal sciences (48 and 20), molecular biology and genetics (170 and 20), environment and ecology (72 and 21), and 310 in cross-fields (interdisciplinary fields; 1,173 and 238). These results suggest that Chinese scientists in the life sciences lagged behind their counterparts.

This does not bode well for Chinese conservation as it competes directly with other life-sciences fields that are also trying to make gains. Unless there is a change in current policies, scientists will continue to shift their research directions away from conservation to other life-sciences branches. Based on these results, China lags behind these two countries in its conservation research capacity as measured by numbers of contributing scientists, conservation-related publications and their average citation indexes in this study, and appears to have neither the human capital nor research quality required to support the implementation of conservation policies locally and regionally in the future.

\section{A blueprint to urgently meet the shortfall}

Without research backing from conservation scientists, policy makers might struggle to make informed decisions, leading to diminishing valuable resources and a deteriorating environment ${ }^{29}$. The dwindling number of vertebrate conservation scientists may impair the ability to achieve the national goal of Ecological Civilization, and may negatively impact biodiversity conservation in countries along the Belt and Road Initiative, where well-trained conservation scientists might be even rarer. We argue that China, given its pursuit of economic growth and scientific excellence in the past decades, is well positioned and equipped to overcome this massive conservation shortfall. We propose several concrete solutions to address these limitations (Fig. 3). We also identify possible agencies, institutions and pathways to implement the practical recommendations.

The need of a different evaluation system. First and foremost, we need to decouple the performance evaluation system from impact factors. It is widely acknowledged that journal impact factors should not be used to rank individuals, especially from different fields $s^{30-32}$. The abuse of impact factors has caused negative effects on individuals and academic society ${ }^{33}$. Many organizations, journal editors and scientists have appealed to fight impact factor abuse $\mathrm{e}^{33}$. The existing evaluation system of the National Natural Sciences Foundation of China (NSFC), the largest scientific grant foundation in China, may be a feasible solution. Although NSFC funding is very competitive, it continues to be an objective and meaningful platform for scientists to contest with their own peers via a single-blind peer-review process. 

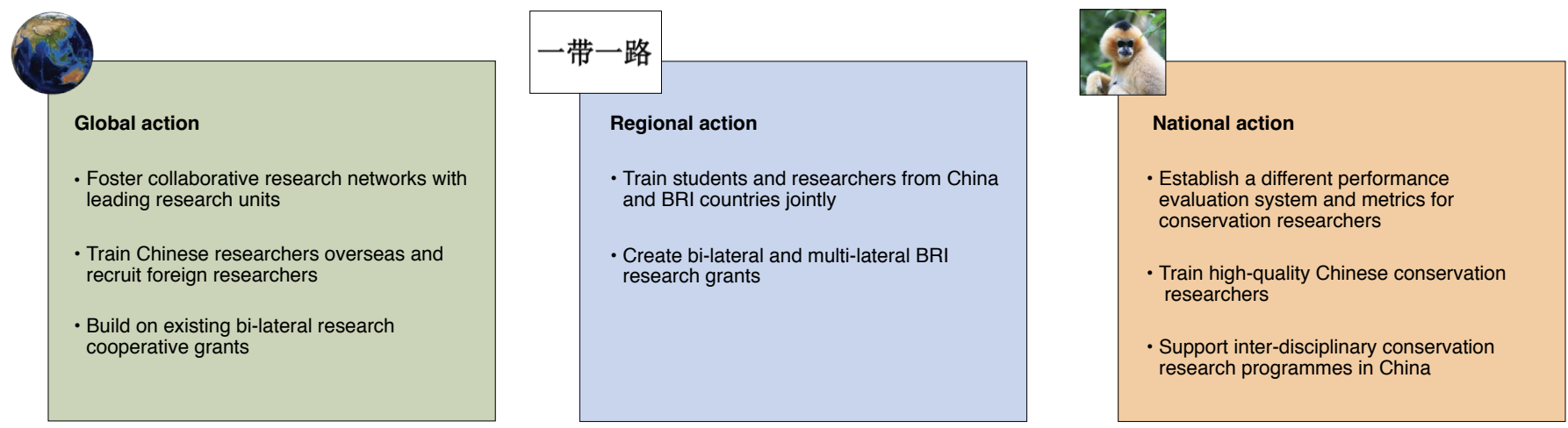

Fig. 3 | A set of national, regional and global recommendations for meeting China's shortfall in local and international conservation needs. The images presented at each level are the adult female northern white-cheeked gibbon (Nomascus leucogenys) (right), the Chinese characters for the Belt and Road Initiative (一带一路) (middle), and the globe (left). Credit: Pixabay (globe image); P.-F.F. (Nomascus leucogenys image).

We propose adopting the NSFC funding peer-review process for intra-institutional performance evaluation. In NSFC grant applications, applicants choose keywords and research directions when they submit their proposals and NSFC matches reviewers according to the keywords and research directions. Institution administrators can request disciplinary peer-review reports during promotion evaluation in the same way. We believe that relying less on an impact-factor-centred evaluation and adopting a concurrent peer-review performance evaluation system could level the playing field for all scientists within the same institution. As such, the fairer peer-review evaluation system may help to reverse the brain drain presently observed among vertebrate conservation scientists.

Promoting training and international exchanges. Second, we need to leverage and scale-up existing recruitment and training policies for conservation rapidly. Chinese universities and research institutes need to create more jobs for early-career conservation scientists. In addition, we should jointly train students locally and overseas through existing funding schemes (for example, the Chinese Scholarship Council, BRI scholarships; and The World Academy of Sciences internationally) to meet domestic and BRI conservation needs. According to a report from the Ministry of Education of China, more than 0.5 million Chinese students were studying abroad in 2016, and $35.5 \%$ of them were masters or PhD students ${ }^{34}$. If Chinese institutions provide more employment opportunities, related research internships and experience, more students will likely major in conservation-related disciplines abroad. Recruiting young Chinese or foreign faculty with overseas $\mathrm{PhDs}$ will also help to reduce academic inbreeding in China (as illustrated in Fig. 1).

From the same report, there were already more than 0.2 million students from 64 BRI countries studying in China in 2016; 69\% of them are graduate students and $61 \%$ of them are supported by Chinese scholarships ${ }^{34}$. To encourage talented BRI students to major in conservation-related disciplines, the Chinese government should set up a new BRI-conservation scholarship fund with a higher quota than other more popular majors. These trained BRI graduates will benefit biodiversity conservation in their native countries, as well as China's global effort in greening the BRI. As the BRI is slated to transform the lives and careers of many scientists, this is the window of opportunity for institutions like CAS and other leading universities to jointly train and build capacity for conservation research in both China and BRI countries ${ }^{35}$.

Encouraging interdisciplinary collaboration. Third, we need to encourage and incentivize existing Chinese vertebrate conservation scientists to conduct more conservation-related research. Effective biodiversity conservation efforts require input and contribution from multiple disciplines, including but not limited to biology, ecology, economics, sociology, psychology, management, and decision sciences. In its present form, conservation in China is still predominantly biological science-based. Novel innovative knowledge institutions created from interdisciplinary collaboration could lead to adaptive learning-based approaches for addressing local conservation issues, where adopting a one-size fits all solution is challenging. Interdisciplinary programmes in China could be modelled after those at the Oxford Martin School at the University of Oxford, UK ${ }^{36}$ and the Earth Institute at Columbia University, US ${ }^{37}$, for example, which are well-known research and policy institutes, where they invest in research and take multi-disciplinary approaches in addressing complex issues such as climate change, ecosystems and illegal wildlife trade. Such programmes could bring together researchers from across disciplines to find conservation solutions in China.

Additionally, establishing endowed chairs in interdisciplinary conservation science research could aid in mentoring young scholars and researchers early into their career to do interdisciplinary research, thereby promoting continuity. Under the backdrop of accelerating biodiversity loss ${ }^{38}$, conservation scientists have the moral responsibility to consider implications of their research for national and global biodiversity conservation. The research to implementation gap is a formidable barrier to successful conservation effort; however, interdisciplinary collaborations may help to bridge and overcome $\mathrm{it}^{23}$. As such, we also encourage conservation scientists to actively engage with practitioners and to participate in conservation decision-making and intervention ${ }^{39}$, where it is critical to ensure that their evidence-based research becomes embedded in practical conservation management and policy. For instance, armed with recent and reliable tiger and leopard population estimates from a network of 2,000 motion-sensing cameras, Chinese conservation scientists were able to advise the Central Government of China to establish a $14,600 \mathrm{~km}^{2}$ Northeast Tiger and Leopard National Park in 2017, which is now one of the largest national parks in China ${ }^{40,41}$.

Fostering international collaborative networks. Finally, due to the geographic scope and impacts of the BRI coupled with weak domestic conservation research capacity, Chinese conservation scientists should actively create and draw on more international conservation networks to collaboratively work on meeting regional conservation needs $s^{14}$. This is particularly important considering that researchers from the UK and USA, and those based in the international agencies, have extensive experience and engagement with local organizations in BRI countries on conservation and development projects, including those across international borders. Existing bi-lateral international cooperative research grants between China's 
NSFC and the US's National Science Foundation and UK's Research Councils $^{42}$; and the United Nations Environment Programme ${ }^{43}$ and from Universities Alliance for Silk Road ${ }^{44}$ could pave the way for joint conservation research initiatives.

Through these recommendations, we believe that the proliferation of Chinese conservation scientists could trigger general conservation science development locally and provide scientific support for China to meet ambitious sustainable development goals such as a green BRI and the growing conservation needs domestically and regionally. In sum, China must urgently act to make up for massive shortfalls in conservation research capacity and research collaborative networks for long-term biodiversity governance.

Received: 7 November 2019; Accepted: 23 June 2020;

Published online: 20 July 2020

\section{References}

1. Jiang, Z. Assessing the surviving status of vertebrates in China. Biodivers. Sci. 24, 495-499 (2016).

2. Liu, J. et al. Protecting China’s bodiversity. Science 300, 1240-1241 (2003).

3. Liu, J. \& Diamond, J. China's environment in a globalizing world. Nature $\mathbf{4 3 5}$, 1179-1186 (2005)

4. Bawa, K. et al. China, India, and the environment. Science 327, 1457-1459 (2010).

5. Jiang, Z. et al. Red list of China’s vertebrates. Biodivers. Sci. 24, 500-551 (2016).

6. Xiao, L. \& Zhao, R. China’s new era of ecological civilization. Science $\mathbf{3 5 8}$ 1008-1009 (2017).

7. Ascensão, F. et al. Environmental challenges for the Belt and Road Initiative. Nat. Sustain. 1, 206-209 (2018).

8. Lechner, A. M., Chan, F. K. S. \& Campos-Arceiz, A. Biodiversity conservation should be a core value of China's Belt and Road Initiative. Nat. Ecol. Evol. 2 408-409 (2018).

9. Liu, X. et al. Risk of biological invasion on the Belt and Road. Curr. Biol. 29, 499-505 (2019).

10. Hinsley, A. et al. Building sustainability into the Belt and Road Initiative's Traditional Chinese Medicine trade. Nat. Sustain. 3, 96-100 (2020).

11. Building the Belt and Road Initiative: Progress, Contribution and Prospects (The State Council Information Office of the Peoples Republic of China, 2019); https://go.nature.com/2RH35rb

12. The Belt and Road Initiative International Green Development Coalition (BRIGC) (UNEP, 2020); https://go.nature.com/3fUotl

13. Ouyang, Z. et al. Improvements in ecosystem services from investments in natural capital. Science 352, 1455-1459 (2016).

14. Zou, Y. et al. China and COP 15: a path for responsible environmental power. Biodivers. Sci. 25, 1169-1175 (2017).

15. Xu, W. et al. Transforming protected area management in China. Trends Ecol. Evol. 34, 762-766 (2019)

16. Wu, R. China's ecosystems: focus on biodiversity. Science 353, 657 (2016).

17. Jiang, Z. et al. China’s ecosystems: overlooked species. Science 353, 657 (2016).

18. SSC Groups (IUCN, 2020); https://www.iucn.org/commissions/ssc-groups

19. Experts (IPBES, 2020); https://ipbes.net/experts

20. The Results of the Fourth National Giant Panda Survey (The State Forestry Administration, accessed 3 May 2017); http://www.forestry.gov.cn/main/72/ content-742880.html

21. Fan, P.-F., Fei, H.-L. \& Luo, A.-D. Ecological extinction of the critically endangered northern white-cheeked gibbon Nomascus leucogenys in China. Oryx 48, 52-55 (2014)

22. Hu, Y. et al. Regional scientific research benefits threatened-species conservation. Natl Sci. Rev. 6, 1076-1079 (2019).

23. Arlettaz, R. et al. From publications to public actions: when conservation biologists bridge the gap between research and implementation. BioScience 60, 835-842 (2010).
24. Horta, H., Veloso, F. M. \& Grediaga, R. Naval gazing: academic inbreeding and scientific productivity. Manag. Sci. 56, 414-429 (2010).

25. Garfield, E. The history and meaning of the journal impact factor. J. Am. Med. Assoc. 295, 90-93 (2006).

26. Lu, X. Hot genome leaves natural histories cold. Science 349, 1064 (2015).

27. Zweig, D. \& Wang, H. Can China bring back the best? The Communist Party organizes China’s search for talent. China Q. 215, 590-615 (2013).

28. Highly Cited Researchers 2019 (Clarivate Web of Science, 2020); https:// go.nature.com/2AYrIKd

29. Cao, S., Wang, G. \& Chen, L. Questionable value of planting thirsty trees in dry regions. Nature 465, 31 (2010).

30. Hicks, D., Wouters, P., Waltman, L., de Rijcke, S. \& Rafols, I. The Leiden manifesto for research metrics. Nature 520, 429-431 (2015).

31. Krell, F. Impact factors aren't relevant to taxonomy. Nature 405, 507-508 (2000).

32. Simons, K. The misused impact factor. Science 322, 165 (2008).

33. Chapman, C. A. et al. Games academics play and their consequences: how authorship, $h$-index and journal impact factors are shaping the future of academia. Proc. R. Soc. B 286, 20192047 (2019).

34. China Exported the Most Number of Students Globally and was the Largest Destination Country for International Students in Asia in 2016 (Ministry of Education of China, 2017); https://go.nature.com/38yWntE

35. Build a sustainable Belt and Road. Nature 569, 5 (2019).

36. The Oxford Martin Programme on the Illegal Wildlife Trade (Oxford Martin School, Univ. Oxford, 2020); https://go.nature.com/2ZOedF6

37. The Earth Institute (Columbia Univ., 2020); https://www.earth.columbia.edu/

38. Pimm, S. L. et al. The biodiversity of species and their rates of extinction, distribution, and protection. Science 344, 1246752 (2014).

39. Sutherland, W. J. \& Wordley, C. F. R. Evidence complacency hampers conservation. Nat. Ecol. Evol. 1, 1215-1216 (2017).

40. Dou, H. et al. Estimating the population size and genetic diversity of Amur tigers in northeast China. PLOS ONE 11, e0154254 (2016).

41. McLaughlin, K. Can a new park save China’s big cats? Science (August 2016); https://go.nature.com/2BDrmse

42. National Natural Science Fund Guide to Programs 2018213 and 218 (National Natural Science Foundation of China, 2018); https://go.nature.com/3hWK7I1

43. BRI Countries. UNEP-IEMP (November 2018); https://go.nature.com/2Vk22i5

44. Sharma, Y. University collaboration takes the Silk Road route. University World News (June 2015); https://go.nature.com/2YuVJKk

\section{Acknowledgements}

C. Ma, K. Shi and X. Zhong assisted in data collection. We thank G. Balachander, S. L. Pimm and T. Mu for comments on an earlier version of the manuscript. This work was supported by research grants from the National Natural Science Foundation of China (grant no. 31822049 to P.-F.F. and grant nos. 41180944 and 41180953 to T.M.L.), and the Guangdong Provincial Research Fund (grant no. 42150016 to T.M.L.).

\section{Author contributions}

P.-F.F., Y.L. and T.M.L. contributed to the writing of this piece. P.-F.F. and L.Y. collected and analysed the data. The project was designed and led by P.-F.F., Y.L. and T.M.L. The senior authors are P.-F.F. and T.M.L.

\section{Competing interests}

The authors declare no competing interests.

\section{Additional information}

Supplementary information is available for this paper at https://doi.org/10.1038/ s41559-020-1253-z.

Correspondence should be addressed to P.-F.F., L.Y., Y.L. or T.M.L.

Reprints and permissions information is available at www.nature.com/reprints.

Publisher's note Springer Nature remains neutral with regard to jurisdictional claims in published maps and institutional affiliations.

(c) Springer Nature Limited 2020 